\title{
José Luis Méndez y Mauricio I. Dussauge-Laguna (Eds.), Policy Analysis in Mexico, UK, Policy Press University Bristol, 2017, 293 pp.
}

Perfiles Latinoamericanos, 26(51)

2018 | pp. 403-408

DOI: $10.18504 / \mathrm{pl} 2651-016-2018$

\section{ए}

estudio del campo multidisciplinario de política pública, a pesar de su corta edad (1951) en comparación con otras disciplinas, ha adquirido un creciente interés que se refleja tanto en el discurso de los políticos y tomadores de decisiones, como en las arengas y demandas de la sociedad civil y en los contenidos de los medios de comunicación, junto con la multiplicación de programas de formación y de publicaciones de distintos tipos e innumerables propósitos, entre los que se halla el conocer, comprender y aprender de procesos decisionales que han desembocado en la resolución de problemas públicos o que han representado obstáculos para revertir situaciones que impactan negativamente en la sociedad.

Policy Analysis in Mexico forma parte de esa inquietud intelectual por visibilizar y comprender el papel que se ha otorgado al análisis de políticas en la toma de decisiones; es un libro que, además de explorar el origen de la lógica bajo la cual ocurren algunos procesos decisionales en México, ofrece elementos valiosos acerca de cómo la gestión de las políticas públicas ha desafiado los cambios político-administrativos del México de los noventa, y muestra las trayectorias profesionales de los responsables de la toma de decisiones, así como de las estructuras organizacionales federales, estatales y municipales de las cuales se esperan decisiones públicas en estricto sentido, es decir, elecciones de políticas que redunden en el bienestar público.

Policy Analysis in Mexico forma parte de un proyecto intelectual e internacional más amplio cuyo propósito es sistematizar bajo pautas compartidas los rasgos que distinguen los procesos decisionales en distintos países a fin de avanzar en su conocimiento a partir de los análisis comparativos de política 
pública. Así lo explicitan los impulsores del proyecto, Iris Geva-May y Michael Howlett, y los editores del caso mexicano, José Luis Méndez de El Colegio de México (Colmex) y Mauricio I. Dussauge-Laguna, del Centro de Investigación y Docencia Económicas (CIDE).

Es así que el libro forma parte de la serie "International Library of Policy Analysis", con la cual se busca recuperar desde la teoría y la práctica el análisis de las políticas públicas en distintos niveles de gobierno, pero sin descuidar el papel de los actores no gubernamentales, ya sea en los procesos o en la toma de decisiones (elección). Dicha serie significa un sólido acervo de conocimiento con miras a un análisis comparativo de políticas, que hasta el momento suma 16 estudios que abarcan todos los continentes: Europa (República Checa, Reino Unido, Noruega, Francia, Alemania), Asia (India, China, Taiwan, Israel, Rusia), América del Norte (Estados Unidos), América Latina (Brasil y México), Oceanía (Australia, Nueva Zelanda) y África (Sudáfrica).

El gran valor del libro editado por Méndez y Dussauge-Laguna radica en que conjuga diversas cualidades que son producto de su estructura y organización, del origen multidisciplinario de sus autores (ciencia política, administración pública, sociología), de las perspectivas analíticas adoptadas, de la articulación entre lo cuali y lo cuanti, y de la selección de sus contenidos.

La perspectiva adoptada resulta atractiva para distintos públicos lectores, estudiosos de las teorías de las políticas públicas, expertos en análisis de políticas y para profesionales en la gestión y administración pública. Los autores pertenecen a distintas instituciones de educación superior (Colmex, CIDE, UIA, UAM, Flacso), lo cual ofrece un sello particular, y los hallazgos de las investigaciones se distinguen por enfatizar en quiénes son parte de los procesos decisionales, en dónde y bajo qué contextos histórico-políticos estos tienen lugar, y qué capacidades en términos de recursos humanos destacan o están ausentes en algunos análisis de políticas que se presentan a lo largo del libro.

Hay que decir que la composición del perfil de los autores favorece el análisis sociológico, politológico y organizacional de las políticas públicas, lo cual se acerca más a una ruta explicativa y de investigación evaluativa de las políticas en el sentido de Carol Weiss, pero sin llegar a ser evaluaciones de impacto. Esto es, la reconstrucción de las decisiones de políticas en esta obra representan el knowledge of de Lasswell $(1971,1992)$, un análisis explicativo de las políticas (Méndez, 1993), un enfoque amplio de políticas públicas (Bazúa \& Valenti, 1993), y lo que actualmente se denomina estudios de políticas (Del Castillo, 2014). Esto significa que las preguntas para las que se busca respuesta se enfocan más en los cómo que en los resultados de un proceso específico de política pública.

Los aportes analíticos y empíricos del libro son importantes ya que todos los casos ilustran singularmente quiénes participan e inciden en los procesos de 
toma de decisiones y qué explica los alcances y límites de esa participación. Aunque frente a este sólido trabajo de investigación y producción de evidencia, se echan de menos las lecciones y recomendaciones de políticas que orienten la ruta del cambio hacia (léase) mejores procesos decisionales con mayor sentido público. Es en esta parte donde el lector encuentra truncas las narrativas pues no sabe qué cambió y/o mejoró los procesos decisionales; todo esto a propósito de rescatar algunas lecciones valiosas para futuros impulsos de cambios de políticas públicas.

El libro se organiza en cuatro partes y quince capítulos, además de la introducción y las conclusiones a cargo de los editores (Méndez \& Dussauge-Laguna).

La primera parte aborda la evolución del análisis de políticas públicas como campo de estudio en México (J. L. Méndez), sin perder de vista su expansión en programas y publicaciones ni el contexto histórico-político del país. En esta parte se establece que, para cumplir los propósitos del texto, el análisis de políticas públicas cobra vida en función de sus metas, aproximaciones y objetos de estudios básicamente en dos áreas: $a$ ) en la evaluación de políticas mediante herramientas específicas, y $b$ ) en el análisis explicativo de políticas, cuyo propósito es describirlas y explicarlas siguiendo una perspectiva secuencial y utilizando aproximaciones teóricas específicas, lo cual queda patente en cada uno de los capítulos.

La segunda parte se dedica al análisis de políticas públicas en el nivel federal. Se desglosan procesos decisionales que ilustran cómo cambian en función de los rasgos de la administración pública (Cejudo); qué tan importantes son, qué aportan y cuáles son los límites de las habilidades burocráticas para la toma de decisiones (Hernández y Arellano); qué papel juega la demanda de servicios especializado de análisis de políticas para la toma de decisiones (Flamand); cómo se toman las decisiones en los recientes organismos constitucionalmente autónomos (Pardo y Dussauge-Laguna), y qué explica el impulso de centros de investigación de políticas públicas en la Cámara de Diputados (Velázquez).

La tercera sección se ocupa del análisis de políticas en los niveles estatal y local, en el marco de dos procesos simultáneos que distinguen a México: la descentralización y la democratización de la década de los noventa, contexto en el que estados y gobernadores adquieren relevancia. En esta sección se revisa también la dimensión política del proceso decisional de las políticas en la Ciudad de México (Olmeda) y se ofrece evidencia sobre el papel de los gobiernos municipales en los procesos decisionales de políticas, a propósito de mostrar que los procesos políticos arriba mencionados no han favorecido la participación de los municipios en ese aspecto (Oliver).

La cuarta parte se enfoca en "el análisis de las políticas más allá del Estado", a fin de llamar la atención sobre los actores no gubernamentales que han 
ganado importancia en los procesos decisionales de política pública. Se trata de la sección más numerosa con seis capítulos, en donde se analiza el papel de los partidos políticos en la toma de decisiones (I. Méndez); la emergencia de think tanks, como el Centro de Investigación para el Desarrollo, A. C. (CIDAC) y el Centro de Estudios Espinoza Yglesias (CEEY), dedicados al análisis de políticas sectoriales para verificar el cumplimiento de logros y metas (Dussauge-Laguna y Vázquez); la incidencia de un conjunto de organizaciones no gubernamentales tradicionales y emergentes en el análisis de políticas tales como Alternativas y Capacidades, Amnistía Internacional, Fundar, Gestión Social y Cooperación y Propuesta Cívica (Somuano); la actuación del sector empresarial (Coparmex, Consejo Mexicano de Hombres de Negocios, Centro de Estudios Económicos del Sector Privado) en las decisiones de política pública, con lo que se muestra que dicho proceso ha estado dominado por el conflicto y la cooperación (Alba); el juego político y el cambio institucional en el mercado laboral, en donde se discute acerca de los actores sociales y políticos del ámbito laboral (Bensusán y Bizberg); y, finalmente, se analizan los medios de comunicación (prensa/radio) para contestar si actualmente en México son más autónomos y profesionales en la cobertura de asuntos públicos, para lo cual fueron seleccionados asuntos específicos como "la casa blanca" de Enrique Peña Nieto al principio de su gobierno, las ejecuciones en Tlatlaya en 2014, y las reformas educativa, energética y de telecomunicaciones (Guerrero, Luengas, Fuentes y Palacios).

Aun cuando se trata de una obra propositiva y bien estructurada, deja muchas interrogantes entre quienes se dedican al estudio de las políticas públicas. Cabe enlistar algunos aspectos que se podrían repensar en pos de la identidad y consolidación del campo de política pública:

- El análisis de las políticas no es un campo de estudio homogéneo. En los abordajes de política pública, en especial si se hacen desde la investigación, presentar algunas de las principales coordenadas del debate actual de política pública resulta útil. A falta de lo anterior en la obra que aquí se reseña, el lector queda a la deriva. Aunque se parte de una amplia perspectiva, conviene hacerle saber a los lectores que no existe una definición única de análisis de políticas o que, en el lado extremo, solo se asume como tal aquel enfoque que pretenda encontrar las mejores alternativas de política pública.

- El análisis de políticas desde la práctica tampoco es un concepto homogéneo; es polémico y polisémico. Sin embargo, en el libro se parte de una concepción tan amplia que finalmente se diluye la decisión, ni más ni menos uno de los objetos esenciales de estudio. En todos los capítulos se pasa 
por alto la útil distinción de Majone entre decisión (elección) y políticas públicas. Es preciso decir que esa distinción es necesaria porque son dos objetos de estudios y/o dos actividades (operaciones) distintas: la decisión es la (mejor) elección que se toma, en tanto que la política pública es la acción específica con la que se atiende la decisión.

- Una singularidad de los análisis explicativos de políticas es la imbricación conocida en inglés como politics-policy, la cual está presente en varios capítulos de la obra e incluso en otros se hace explícita. Pero no hay mayor elaboración teórica de dicha relación a fin de identificarla en el caso de México. Lo anterior exige la construcción de marcos teórico-analíticometodológicos que den cuenta de los rasgos y la dirección de la relación entre los conceptos del binomio politics-policy.

- Actualmente existen avances significativos respecto de la conceptualización de los actores que participan en los procesos de política pública, sin embargo, el libro es omiso en esa parte, pese a que se destaca por dar visibilidad a distintos actores. Esta situación se debe de algún modo a que la literatura de referencia tiene como foco los procesos políticos y no el papel de los actores en los procesos de política pública.

- Por último, se debe reiterar la relevancia de finalizar las investigaciones de políticas como lecciones y/o recomendaciones; a fin de cuentas es lo que de alguna manera le brinda singularidad al análisis de políticas públicas.

Por todo lo aquí reseñado, resulta una obra muy recomendable de leer, especialmente porque se trata de un esfuerzo intelectual que abona a la amplia discusión del mundo de las políticas en México.

\section{Referencias}

Bazúa, F. \& Valenti, G. (1993). Hacia un enfoque amplio de política pública. Revista de Administración Pública, (84), 25-82.

Del Castillo, G. (2014, marzo). Una perspectiva analítica de política pública para el análisis de problemas públicos complejos. Conferencia en el IV Congreso Nacional de Ciencias Sociales, Consejo Mexicano de Ciencias Sociales.

Lasswell, H. (1992). Orientación hacia las políticas. En Aguilar Villanueva, L. F. (Ed.). El estudio de las políticas públicas (pp. 79-103). México: Porrúa.

Majone, G. (1992). Los usos del análisis de políticas. En Aguilar Villanueva, L. F. (Estudio introductorio y ed.). La hechura de las políticas (pp. 341-366). México: Porrúa. 
Méndez, J. L. (1993). La política pública como variable dependiente: hacia un análisis más integral de las políticas públicas. Foro Internacional, 33(1), 111-144.

Weiss, C. (1977). Research for policy sake: The Enlightenment function of social research. Policy Analysis, 3(4), 531-545.

\section{Gloria Del Castillo Alemán*}

* Profesora-Investigadora de Tiempo Completo de la Flacso México. 